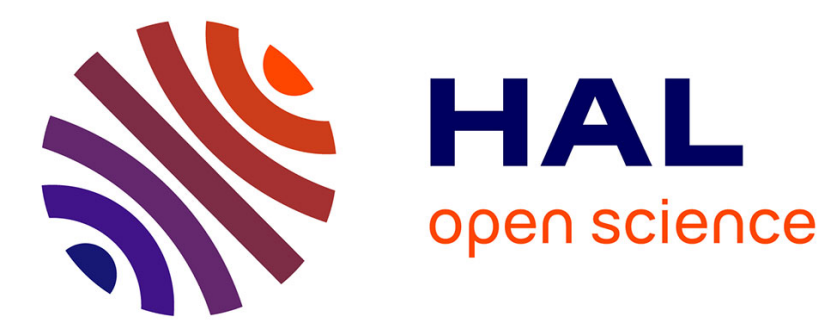

\title{
ERASMUS TALKING AND DOING
}

Jean-Paul Becar, Jean-Charles Canonne, Marika Seppälä

\section{To cite this version:}

Jean-Paul Becar, Jean-Charles Canonne, Marika Seppälä. ERASMUS TALKING AND DOING. 10th International Conference on Education and New Learning Technologies, Jul 2018, Palma, France. 10.21125/edulearn.2018. hal-02508939

\section{HAL Id: hal-02508939 \\ https://uphf.hal.science/hal-02508939}

Submitted on 16 Mar 2020

HAL is a multi-disciplinary open access archive for the deposit and dissemination of scientific research documents, whether they are published or not. The documents may come from teaching and research institutions in France or abroad, or from public or private research centers.
L'archive ouverte pluridisciplinaire $\mathbf{H A L}$, est destinée au dépôt et à la diffusion de documents scientifiques de niveau recherche, publiés ou non, émanant des établissements d'enseignement et de recherche français ou étrangers, des laboratoires publics ou privés. 


\title{
ERASMUS TALKING AND DOING
}

\author{
Jean-Paul Bécar ${ }^{1}$, Jean-Charles Canonne ${ }^{1}$, Marika Seppälä ${ }^{2}$ \\ UVHC, IUT GEII Valenciennes (France) \\ ${ }^{2} S A M K$, PORI, (FRANCE)
}

\begin{abstract}
I am Erasmus or I was Erasmus are coming common words in the European community. The article deals with that background and over two decades practice on European exchanges. Three major parts detail the theoretical background about Erasmus exchanges and its settings, the complete process of exchange and the final outcomes. Each part points out the student, teacher, researcher, staff points of view. Except the first part of the paper, giving a description of Erasmus exchanges, the rest of the paper contains completed experiences. Erasmus is an acronym for EuRopean community Action Scheme for the Mobility of University Students. Launched since 1987, the Erasmus program is labeling the universities as academic structures for European citizen. The three following topics are setting the main objectives of the Erasmus program. That are Increase significantly mobility and promote broad and intensive cooperation between universities, Harness the full potential of the universities by means of increased mobility of teaching staff and Make the name European citizen as a reality. The mobility reveals three new items as Motivation, Mind and Money. Motivation makes the mobility a reality. The mobility induces a deep mind changes for most of attendees. The discovery of one real life country is building their own opinion on what is provided thus distorted by most of medias and also the internet except some shared experiences and what is practiced. For students, the mobility offers a gap to get from a virtual world into a real one splashing large material aspects. One of them is the money invested in the process. It comes mainly from European Community and the rest from personal funding. Questions are rising up for material details and pedagogical aspects of the placement. Main details are checked by the International Relationship Office. The staff is playing a decisive role as an interface between the student, the supervisors teachers and the partner universities. Main mobilities treated here for students are concerned with a three months placement in partners universities. During the stay the students discover a new environment, new teaching methods and must adapt themselves to this new universe. Examples of placement are proposed to the reader according to the welcome country. Some statistic data are also presented. One of the main impact for the student is to enter the success spiral. The mind is changing and opening and autonomy is growing up. These elements make the decision more favorable for a company manager to recruit that type of profile. The teachers involved in the process are featuring their dynamic department. It implies good opinions for their forthcoming and loved promotion. One question is rising up at any time of placement is about the process itself. Is the success due to the European Community rules or to men and women involved in it.
\end{abstract}

Keywords: Exchanges, lab projects, Erasmus+,

\section{INTRODUCTION}

"Erasmus of Rotterdam Erasmus Desiderius 1465-1536, lived and worked in several parts of Europe, inquest of the knowledge, experience and insights which only such contacts with other countries could bring" wrote the European Commission on its website.

ERASMUS is an acronym for European community Action Scheme for the Mobility of University Students. The basic idea was created by Alan Smith who found the name based on words: University, Student, Action, Mobility, Europe.[1]

I am Erasmus or I was Erasmus are coming common words in the European community. The article deals with that background and over two decades have practiced the European exchanges $[2,3]$.

Launched since 1987, the Erasmus program is labeling the universities as academic structures for European citizen $[4,5]$. The three following topics are setting the main objectives of the Erasmus program. That are Increase significantly mobility and promote broad and intensive cooperation between universities, Harness the full potential of the universities by means of increased mobility of teaching staff and Make the name European citizen as a reality[6,7]. 
Involved in the Erasmus process since almost two decades, the authors as their students after stays are considering themselves are European citizen. Their respective universities are collaborating within this background for teachers exchanges and students exchanges as their institutes share the same and wide electrical engineering domain and the same point of view about other teaching methods applied to motivate the students.

The mobility reveals three new items as Motivation, Mind and Money. Motivation makes the mobility a reality. The mobility induces a deep mind changes for most of attendees. The discovery of one real life country is building their own opinion on what is provided thus distorted by most of medias and also the internet except some shared experiences and what is practiced. For students, the mobility offers a gap to get from a virtual world into a real one splashing large material aspects. One of them is the money invested in the process. It comes from European Community, regional scholarships and from personal funding.

The paper deals with completed experiences in the Erasmus background process.

The section two presents the Erasmus process applied to the electrical engineering department of the Institute of Technology. The section provides details on the organization placement subject section is pointing out on what has been done locally. The exchanges are mainly concerned with placement at partner universities for learning and lab projects. They took three months. Some lab projects are proposed to the reader with comments from the students themselves.

The section three is presenting some data about exchanges. The section provides some impact factors for students, teachers, staff and universities.

In conclusion, the first author opinion is given to the reader and some elements for later improvement in the Erasmus+ background exchange process are proposed.

\section{THE ERASMUS PROCESS}

The Erasmus program is labeling the universities as academic structures for European citizen. The three following topics are setting the main objectives of the Erasmus program. That are Increase significantly mobility and promote broad and intensive cooperation between universities, Harness the full potential of the universities by means of increased mobility of teaching staff and Make the name European citizen as a reality.

\subsection{The Institute of Technology}

The creation of Institute of Technologies in France was decided on sixties. The aim was to provide French companies with qualified employees specialized in fast developing technologies to bring help to engineers and companies in their efforts to modernization. The creation of Institutes of Technology was also part of territorial management. As Universities are only located in bigger towns, the creation of Institute of Technology in medium-sized cities is an opportunity to bring new technologies everywhere in the country to help local companies. It is also an opportunity to bring more young people to new jobs, in particular people from families with low income, who could not afford studies in bigger and more expansive towns. The Institute of Technology is one of them (http://www.iutenligne.net/). According to their academic syllabus, one third of courses thus final marks is concerned with a placement in company or in a partner university that is detailed below (http://www.univ-valenciennes.fr/) .

\subsection{The local organisation}

The success spiral or constant improvement is the rule that leads the article. Started fifteen years ago with only one teacher and two students going abroad, five teachers have joined the process of exchanges and about twenty students a year are going abroad in a three months Erasmus placement for regular courses.

The following details the long process for any student decision to go abroad. At the Institute of technology, any student is taking part to a two years course in order to obtain a diploma with the chosen speciality. The Erasmus process is launched one year in advance. An academic and official 
presentation of stays and their logistics, the partners and their proposed subjects is given in front of the audience receiving an information torrent. All year long, many questions arise to the staff for details and previous experiences. The teacher availability involved in the process, the already visited partner university by the teacher and some feedback of former students discussing in social networks are preparing the student decision to go abroad. During this first year, the student understands and practises what is the electrical engineering domain and its applications and what is done abroad. At the starts of the next academic year, the decision is taken to go abroad for three months placement. At the partner university, any supervisor is proposing projects for a two students group. The local department staff validates the student choice after taking account of the level in English language, the subject matching to the student skills and performance. The process is now launched. It requires many necessary, unavoidable and time consuming paperwork. It takes over six months to gather all needed documents. That are the forms to be filled by the student, the local administration and the partner university. To attest the English level for the success at the stay, a multiple choice on line questionnaire is given to the attendee in order to validate the English level on the scale $A 1, A 2$, $\mathrm{B} 1, \mathrm{~B} 2, \mathrm{C} 1$ and $\mathrm{C} 2$. Once the folder accepted to go abroad, a link coming from UE is send to the student mail in order to be filled within a couple of days. A level certificates validates the stay. Sometimes, it happens the English level is not sufficient to accept the student mobility. In that case, the authorisation of the sending university is required by the teacher confirmation.

Once the bureaucracy is done, a new set of question is arising from students about the accommodation, the everyday life cost and the fund to be planned before the stay.

The funds for students placement are coming from different sources. The student in a summer job saves money in order to be more autonomous according to free from their parents. If the Erasmus scholarships covers a wide part of the mobility, the rest of money is given by a regional scholarship. This is one answer to inhabitants at the heavy fiscal pressure. In background, most of parents are helping them while giving money in advance as none euro coming from any scholarship is given before the placement. Once the placement is launched, the student proves his installation at the partner university and receives eighty of all a couple of days later. The rest is obtained back in France.

\subsection{Some projects and their management}

The subjects at partners university are mainly electrical engineering oriented. They include a part of theoretical lessons and the rest in project $[8,9]$. In the following, some projects are offered to the reader. The comments from teachers or students point out their impact either on minds or staff or academics.

Filtering: The Design and implementation of band-pass digital filters based on a microprocessor system Application on Cochlear prosthesis. This project was led in Spain by only one french student. $\mathrm{He}$ improved his basic spanish language elements and got new skills in electronics. Particularly mature thus autonomous, he definitively promotes both institutes.

Using a micro processor: The project -A smart finger with micro processor connection- was proposed by a University in Portugal. A group of two students work altogether in the mechanical, electrical, computer science domains. One of them chose a course in bachelor of technology in the embedded electronic domain in order to go abroad next academic year. The students in placement discovered the use of a cheap but efficient microprocessor. They bring back this way to teach at home. Since three years, the Electrical engineering department is using the micro processor Raspberry $\mathrm{Pi}$ for projects and recently for a computer vision course.

$A$ virtual process design: the project given in a Romanian University deals with a virtual prototyping method is a kind of engineering method which can shorten new product development cycles by replacing cost physical prototype with virtual digital model. For any placement, the student himself defines the project thanks to the previous projects which can be checked on the library and to their supervisor which is giving advises for a project and guaranties the success.

An electrical drive motor: Installing an electrical drive motor on a combi Volkswagen. This subject has been given to a group of 4 french students working at a Finnish University with a group of 4 Finnish students. It covered most of the domain taught in electrical engineering topic. That kind of activities is quasi impossible to organize in a normal course full of lectures, homeworks and practical works. The Erasmus placement is opening facilities to work all day long.

A feedback force joystick: The feedback force joystick based on the rational Bézier curves representation with mass point was the first project proposed in France fifteen years ago at two 
Finnish students well informed on the Erasmus process. It was the first time our department received European students and the first time for the author to manage and supervise such a hard subject. The subject was mixing the applied mathematics to curves and surfaces in a representation also called representation by mass points and computer science in order to program a feedback force joystick acting on control points. A briefing was planned once a week. The availability of the supervisor made the project completed. Since that placement the student behaviour is always mentioned in lectures for French because, every briefing a week was ending by this step beyond rule : "I'll try".

For all lab projects abroad, one French supervisor is devoted to check the work done weekly as the student must send by mail a short description of already done work, the next tasks to do and comments. A final report and a presentation is given back in order to obtain the marks for the stay. Thanks to teacher mobility, the supervisor goes and visits the group of students and participates to the everyday life of the group. The opportunity is given to reinforce the links between both universities and discover new collaborators and equipment if any. And also to discuss and share experiences on pedagogical innovations or applications.

The next section deals with the main outcomes of the exchanges. Some statistic data and some impact factors are presented.

\section{OUTCOMES}

\subsection{Statistics data}

The European Community is giving to each citizen an access to all studies on the Erasmus+ exchanges for any country and for any course( https://ec.europa.eu/programmes/erasmusplus/.../annual-report-2016-stat-annex en.pdf)

The figure 1 shows the growing of exchanges and in particular the number of mobilities for a stay became twice within five years. The data also mention the number of stays is concerned with bachelors mainly. (http://www.statisticsforall.eu/maps-erasmus-students.php )

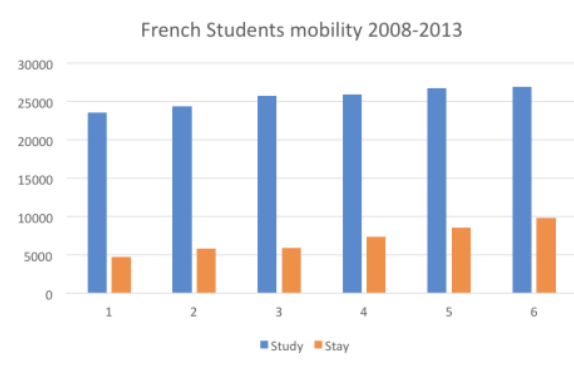

Figure 1: Mobility in France from 2008 to 2013

A more recent data about the mobility is shown on figure 2. The set of diagrams deals with the mobility from 2013 to 2016. All sources are coming from the International Relationships Office at the University of Valenciennes. On figure 2 left, the mobility is concerned with the whole University. The figure 2 center, the data show the mobility for the Institute of Technology. The figure 2 right shows the mobility that is a mix between study and stay as the students are going abroad for three months including some study and a laboratory project.

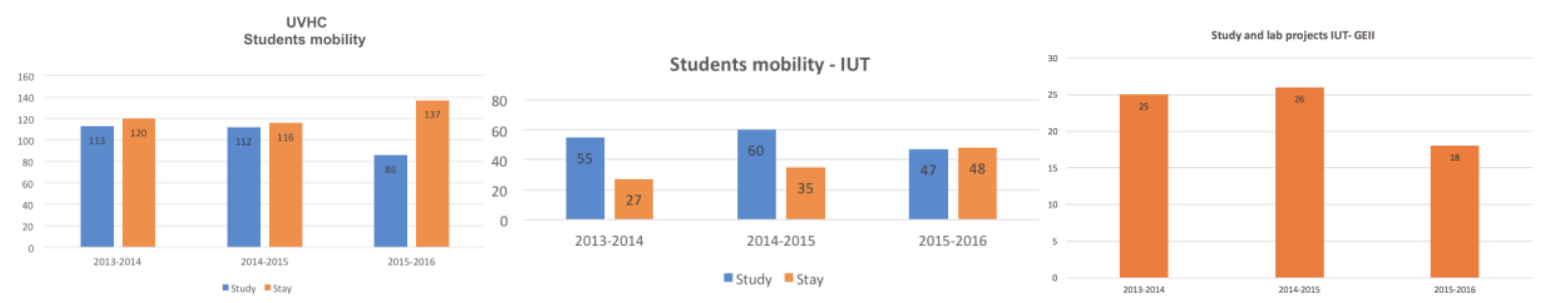

Figure 2: Mobility at University of Valenciennes(left) IUT (center) GEII-Department (right)

from 2013 to 2016 


\subsection{Impact factors}

Erasmus training or teaching mobility : as mentioned above, the Erasmus teaching mobility provides an opportunity to visit students in placement. Moreover, as the authors did it, the Erasmus staff training mobility offers new contacts. Nevertheless, the connection will be better when discussing with teachers in the same domain or in a close domain.

Dynamic : the numbers of students going a broad a year induces two consequences. First, a dynamic image is shown to the forthcoming students during pedagogical events as opening day. On a second hand the institution is getting more attractive.

A international week: the contacts and links with partners ease the organisation of an intensive week for apprentices. Some local or national companies propose a contract with the Institute of technology for students who have passed their baccalaureate exam. The future technician will share his time in the company and at the Institute of technology. The company is giving a salary to its employees and to the Institute in order to acquire new skills. At the Electrical engineering department, the work period and the learning period are switched each month. In the apprentices schedule an international week is planned and totally financed by the companies where they work. Nevertheless, one condition is that the student-technician is considering the week as part of his legal annual leave. During that week, the French technician discover a new world. Culture, behaviour, environment, lessons and projects in English language, team working are the main topics for this intensive week.

English practising : From the point of view of outgoing students, the opportunity is given to learn, talk and practise technical and common English language in real situations. As main documentations, particularly in the software background, are written in English language, future technicians must know and practice the classical terms on their basic domains applied in the stay.

Self awareness : A consequence of the placement abroad is the student opens himself the door to a new world. Some of them decide back in France to chose the next year academic course that offers a placement abroad in another country. The new skills in practicing English language in a technical domain as in everyday life participate in the motivation.

\section{CONCLUSION}

The paper presents a short description on what is Erasmus+ for students, teachers and researchers and staff. It mainly focuses on experiments done since fifteen years at the Electrical Engineering of the Institute of Technology. It tries to give the impact of the exchanges either for outgoing students or for teachers-researchers in training/learning time.

The Erasmus+ process takes a long time to launch new agreements. The link between universities depends on men and women involved in this dynamic but also the EC rules for agreement and funding. It happens that in the running career promotion train, some colleagues quite involved in the exchange process are left on the bound. The frustration feeling that follows does not encourage younger colleague to going on. Efforts by the system should be done in that sense. This the reason why this paper tends to answer one question: is the EC rules that make the connection between men and women from different universities or are men and women involved in the process that contributes to improve the European Community.

Anyway, teachers, researchers, technicians, staff members, students and apprentices once back home have the sensation to be a European Citizen.

\section{ACKNOWLEDGEMENTS}

The authors warmly thank the European community, their partner universities and the colleagues in their respective International Relationships Offices in particular Marika, Nina, Outi, Tauno, Ismo, Markku, Petteri, Harri, Aari, Sirpa from Finland (www.samk.fi) Abdenour, Mourad from Finland (www.oamk.fi) Désiré, Marcin, Witold, Piotr, Arek from Poland (www.pw.pl) Andzej, Arek, Wojciech from Poland (www.pb.pl) Aurel, Mariana from Romania (www.unitbv.ro), Michael, Rainer, Ralf from Germany (www.ho.de) Juan, Antonio, Carina, Beatriz, Tati, Angel, Carlos from Spain (www.upct.es) 
Luis, Ana Cecilia, Hugo, Neide from Portugal (www.ipl.pt), Alma, Virginijus from Lituania (www.ktu.edu) and Sébastien, Jutta, Valériane, Jonathan, Amandine, Maria, Fatia from staff (http://www.univ-valenciennes.fr/IUT/les-relations-internationales ) and also Laurent, Eric, Benoit, Pascal, Caroline, Fabrice, Alain (http://www.univ-valenciennes.fr/lUT/ )

\section{REFERENCES}

[1] A. Smith, Joint programmes of study : an instrument of European cooperation in higher education, Commission of the European Communities, 1978

[2] J.-P. Bécar , L. Vermeiren , J.-C.Canonne , F. Robert, G. Longé, L'effet catalyseur des échanges Erasmus, Actes du 16ème Colloque National de la Recherche en IUT, 9, 10 et 11 Juin 2010, IUT d'Angers.

[3] J.P. Becar, J.C. Canonne, E. Cartignies, M. Fratu, A. Fratu, M. Iwanowski, W. Czajewski, Three experiments of learning by examples, 9h International Technology, Education and Development Conference, Madrid, Spain. 2-4 March, 2015. ISBN: 978-84-608-5617-7 / ISSN: 2340-1079

[4] B. Feyen, E. Krzaklewska, The ERASMUS Phenomenon - Symbol of a New European Generation, Peter Lang International, Frankfurt 2013.

[5] Gr. Makrides, Y. Kalaitzis, Eracon 2016\&2017 proceedings, ISBN 978-9963-2173-4-2

[6] Impact de la mobilité européenne des enseignants \& des personnels administratifs, Centre international d'études pédagogiques, Agence Europe Education Formation France, Bordeaux, 2013.

[7] Erasmus+ Building on experience: Testimonials of Erasmus Mundus promotion projects, Agence Exécutive Education, Audiovisuel et Culture, Bruxelles, 2016.

[8] S. Mailles-Viard Metz, L Hung, M., Pélissier, C. Kennel, Le projet: les pratiques en IUT, L'Harmattan, (2016) ISBN : 978-2-343-10803-2.pp. 4-6.

[9] J.-P. Bécar, J.-C. Canonne , M. Seppälä, A. Mayeur, Computer Aided Teachings Systems, in EDULEARN16 Proceedings ISBN: 978-84-608-8860-4. 